\title{
A Absorção do Cobre pela Cana de Açúcar Co 419 em função da idade
}

A. O. JACINTHO, R. A. CATANI e D. PELLEGRINO

Escola Superior de Agricultura "Luiz de Queiroz", USP Piracicaba, S. Paulo 


\section{INTRODUÇÃO}

O cobre é um micronutriente essencial às plantas. Está presente como parte ativa em muitas enzimas, como a polifenoloxidase, de grande importância nos processos respiratórios das plantas em crescimento (BONNER, 1950).

O cobre é também grupo prostético, essencial para o funcionamento da tirosinase, que ataca o amino ácido tirosina, e da oxidase do ácido ascórbico que ataca e destrói o citado ácido (BONNER, 1952).

JACKSON (1958), fazendo uma compilação sôbre a distribuição de diversos elementos nas plantas cultivadas, citou concentrações de cobre variando de 3 a $200 \mathrm{ppm}$, em tecidos de 15 espécies de vegetais.

Para o caso particular da cana de açúcar, EVANS (1955), encontrou em análise foliar, variações de menos de $4 \mathrm{ppm}$ a mais de $10 \mathrm{ppm}$, sendo que a maior frequência estava entre 5,1 e $6,0 \mathrm{ppm}$.

EVANS (1959), notou também que as lâminas das fôlhas de cana, com mais de $5 \mathrm{ppm}$ de cobre não apresentavam sintomas precisos de deficiência. $\mathrm{Na}$ realidade, os citados sintomas aparecem quando o teor de cobre desce para 3,7 a 3,5 ppm.

HUMBERT (1963), indica que os níveis mais altos de cobre na cana se encontram no anel de crescimento e nas regiões de cêra. O mesmo autor, cita experimentos com 3 variedades diferentes de cana adubadas, onde foram encontradas de 0,9 a $34 \mathrm{ppm}$ de cobre, para as diversas partes da planta em idades variando de 3 e 4 a 19,23 e 24 meses.

CATANI, ARRUDA, PELLEGRINO \& BERGAMIN FILHO (1959), trabalhando com cana de açúcar variedade Co 419 , crescendo em condição de campo, na região de Piracicaba, obtiveram uma série de dados referentes à absorção de vários nutrientes em função da idade da planta. Em sequência a êsse trabalho PELLEGRINO \& OUTROS (1962) conseguiram dados referentes a manganês e zinco.

GLÓRIA \& OUTROS (1963) obtiveram nas mesmas condições, dados sôbre molibdênio e BITTENCOURT \& OUTROS (1963) em continuação aos demais obtiveram dados referentes a absorção do ferro. 
O presente trabalho, em continuação a aquêle iniciado por CATANI \& OUTROS (1959), tem por objetivo conhecer a concentração de cobre existente no côlmo e na fôlha da cana de açúcar, variedade Co 419 , assim como determinar a quantidade do citado elemento que é absorvida pela planta, durante o seu desenvolvimento.

\section{2 - MATERIAL E METODO}

As amostras constam de 4 touceiras de cana, variedade Co 419, colhidas mensalmente de um experimento com 3 canteiros adubados com $40 \mathrm{Kg}$ de nitrogênio (sulfato de amônio), $100 \mathrm{~kg}$ de $\mathrm{P}_{2} \mathrm{O}_{\text {, }}$ (superfosfato simples) e $40 \mathrm{Kg}$ de $\mathrm{K}_{2} \mathrm{O}$ (cloreto de potássio) por hectare na época do plantio. O experimento foi instalado na Estação Experimental de Cana "Dr. José Vizioli" Piracicaba, Estado de São Paulo. Destas touceiras separaram-se colmos e fôlhas (só a parte aérea) e êste material foi preparado mensalmente para análise, conforme foi descrito por CATANI \& OUTROS (1959).

O método utilizado para a determinação do cobre no presente trabalho é o do dietilditiocarbamato de sódio já empregado por JOHNSON \& ULRICH (1959), com a modificação de que ao invés de se usar EDTA amônio em tôrno de $25 \%$ como agente complexante dos íons interferentes, usou-se EDTA dissódico a $1 \%$. As leituras foram feitas em espectrofotômetro Beckman, Modêlo B, em comprimento de onda de 440 milimicrons.

\section{Reagentes:}

Solução de dietilditiocarbamato de sódio a $1 \%$. O reagente foi preparado, dissolvendo-se $1,0 \mathrm{~g}$ do sal Merck p.a. em $100 \mathrm{ml}$ de água desmineralizada. Esta solução deve ser recente e guardada em ambiente fresco.

Soluç̃a de etilenodiaminotetracetato de sódio a 1\%. Esta solucão foi preparada dissolvendo-se $10,0 \mathrm{~g}$ do sal dissódico do ácido etilenodiaminotetracético, com duas moléculas de água. Titriplex III Merck, em um litro de água desmineralizada.

Soluçâo de hidróxido de amônio $(1+1)$. Um volume dé $\mathrm{NH}_{4} \mathrm{OH}$ concentrado e destilado foi diluido com igual volume de água desmineralizada. 
Solvente:

Foi usado o tetracloreto de carbono Mallinckrodt, (Analytical reagent).

Indicador:

Soluç̃̃o alcoólica de fenolftaleina a $0,1 \%$.

Prenaro dos padrões de cobre.

Solucão estodue - Foram dissolvidos $393,0 \mathrm{mg}$ de $\mathrm{CuSO}_{4}$. 5 H.O Baker p.a. em água desmineralizada, transferiu-se para balão volumétrico de 1 litro, adicionaram-se $5 \mathrm{ml}$ de $\mathrm{H}_{2} \mathrm{SO}_{4}$ concentrado Baker p.a., esperou-se esfriar e completou-se o volume. Esta solucão contém $100 \mathrm{ppm}$ de cobre por ml.

Solucão de trabalho ... Foram preparadas à partir da solurãn estonue e da sepuinte maneira: $5,10,15,20$ e $25 \mathrm{ml}$ da solucão estoque foram transferidos para balóes de $100 \mathrm{ml}$ e comnletados os volumes com água destilada. Estas solucões contém, respectivamente, 5. 10, 15, 20 e 25 microgramas de cobre por $\mathrm{ml}$.

Preparo da curva padrão.

Tomou-se $1 \mathrm{ml}$ de cada solucão de trabalho, transferiu-se nara funil de senaracão de $125 \mathrm{ml}$. adicionaram-se $50 \mathrm{ml}$ da colurão de EDTA dissódico a $1 \%$, 3 gôtas de fenolftaleina e homogeneizou-se. Em seguida, adicionaram-se $\mathrm{NH}_{4} \mathrm{OH}$ (1) 1) até viragem do indicador para côr rosa estável, $25 \mathrm{ml}$ da solurão de carbamato e exatamente, $10,0 \mathrm{ml}$ de solvente CC1. Procedeu-se de igual maneira para a prova em bran$\mathrm{cr}$. Os funis foram aoitados vigorosamente durante $2 \mathrm{mi}$ nutos. Anós a aqitacão esperou-se a separacão das fases e o solvente foi drenadn nara as cubetas do espectrofotômetro, o aual foi aiustado para comprimento de onda de 440 milimicrons e procedeu-se às leituras. Uma relação linear entre densidade ótica e concentração das soluções foi obtida.

\section{Determinação do cobre na cana.}

Pesaram-se 500,0 $\mathrm{mg}$ da amostra, transferiram-se para Kjeldahl de $30 \mathrm{mi}$, adicionaram-se $10 \mathrm{ml}$ de $\mathrm{HNO}_{3}$ concentrado e destilado e 3 gôtas de $\mathrm{H}_{2} \mathrm{SO}_{4}$ concentrado Baker p.a. Levou-se ao dimcstor e o aquecimento inicial foi feito em fogo 
brando até que tivesse sido interrompida a formação de espuma e após, o aquecimento foi mais intenso. Quando o líquido apresentou-se amarelado e grande parte do ácido nítrico havia sido eliminado, o Kjeldahl foi retirado do digestor e esfriado. Adicionaram-se $2 \mathrm{ml}$ de ácido perclórico Baker $70-72 \%$ e levou-se novamente ao digestor, com o aquecimento aumentado progressivamente até o líquido apresentar-se incolor. Continuou-se o aquecimento até desprendimento de fumos brancos de ácido perclórico. Conduziu-se ao mesmo tempo uma prova em branco.

Após esfriar o material do Kjeldahl, transferiu-se para funil de separação de $125 \mathrm{ml}$, lavando-se o balão com 5 porções de $10 \mathrm{ml}$ de EDTA dissódico a $1 \%$ e adicionando-se 3 gôtas de fenolftaleina. Daqui por diante procedeu-se de igual maneira, já descrita para os padrões.

As leituras foram feitas nas mesmas condições dos padrões, contra a prova em branco. Calculou-se a concentração em ppm de cobre nas amostras, em função da relação linear entre densidade ótica e concentração das soluções, feitas para os padrões.

\section{3 - RESULTADOS OBTIDOS}

Os dados relacionados no quadro 1 , expressam a concentração de cobre no côlmo e fôlha da cana de açúcar em função da idade da planta, de acôrdo com o mês de colheita da amostra.

\section{QUADRO 1}

Concentração e ppm de cobre, no côlmo e na fôlha da cana de açúcar variedade Co 419, em função da idade (material sêco).

\begin{tabular}{lccc}
\hline $\begin{array}{c}\text { Época da colheita } \\
\text { das } \\
\text { amostras }\end{array}$ & $\begin{array}{c}\text { Idade da } \\
\text { planta } \\
\text { em meses }\end{array}$ & $\begin{array}{c}\text { Concentração de côbre em ppm } \\
\text { côlmo } \\
\text { fôlhas }\end{array}$ \\
\hline \hline outubro & 6 & 62,8 & 30,0 \\
novembro & 7 & 42,8 & 15,0 \\
dezembro & 8 & 34,2 & 11,2 \\
fevereiro & 10 & 30,0 & 18,6 \\
março & 11 & 41,4 & 11,2 \\
abril & 12 & 7,4 & 12,4 \\
maio & 13 & 13,6 & 10,0 \\
junho & 14 & 32,8 & 30,0 \\
julho & 15 & 18,6 & 20,0 \\
\hline
\end{tabular}




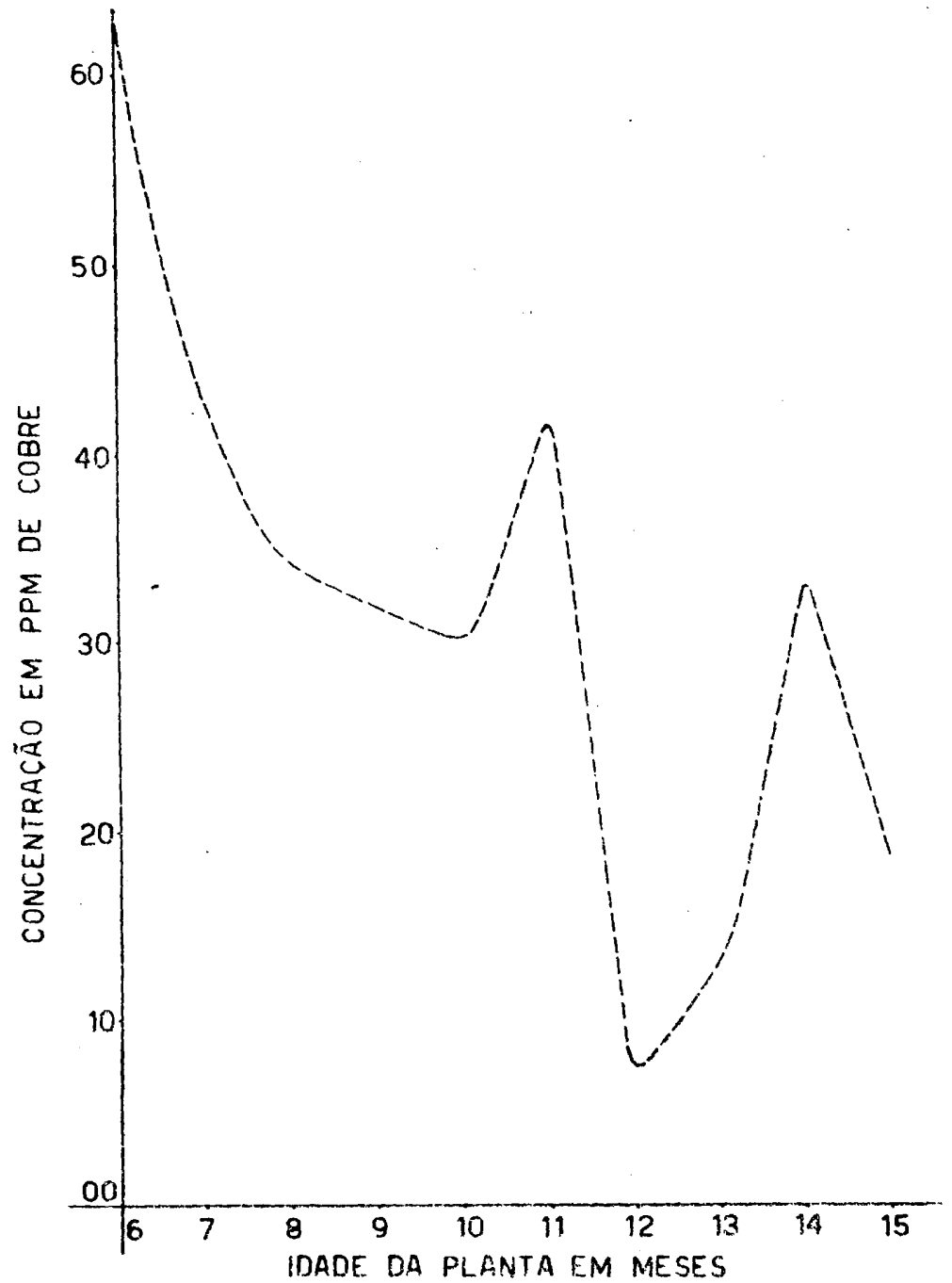

Figura 1-Voriaça do teor de cobre, em ppm, nos colmos de cana-de-acuicar, variedade Co 419, de acôrdo com a idade da plania. 


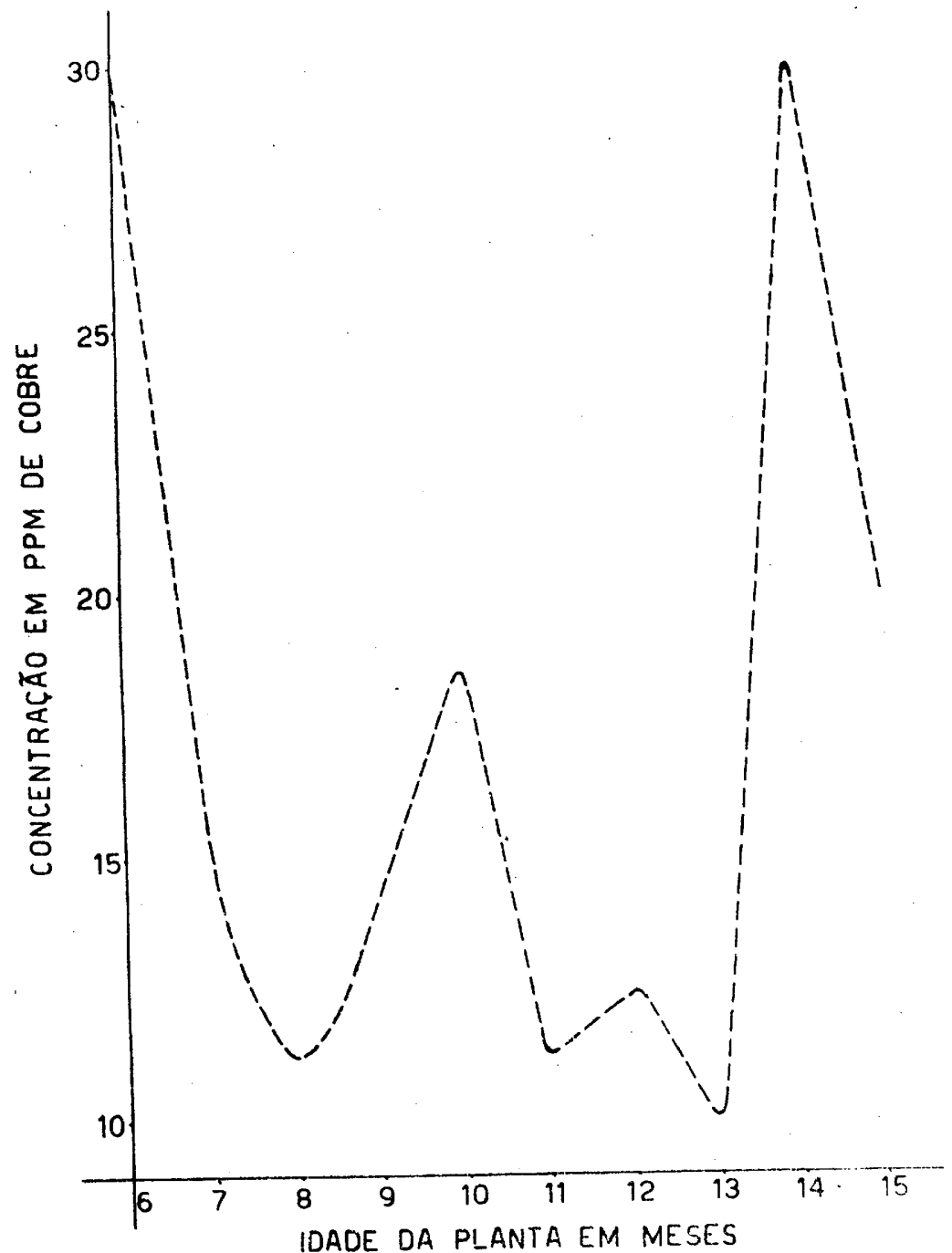

Figura 2 -Variaçăo do teor de cobre, em ppm, nas fôlhas de cana-de-acuicar, variedade Co 419, de acôrdo com a idade da planta. 


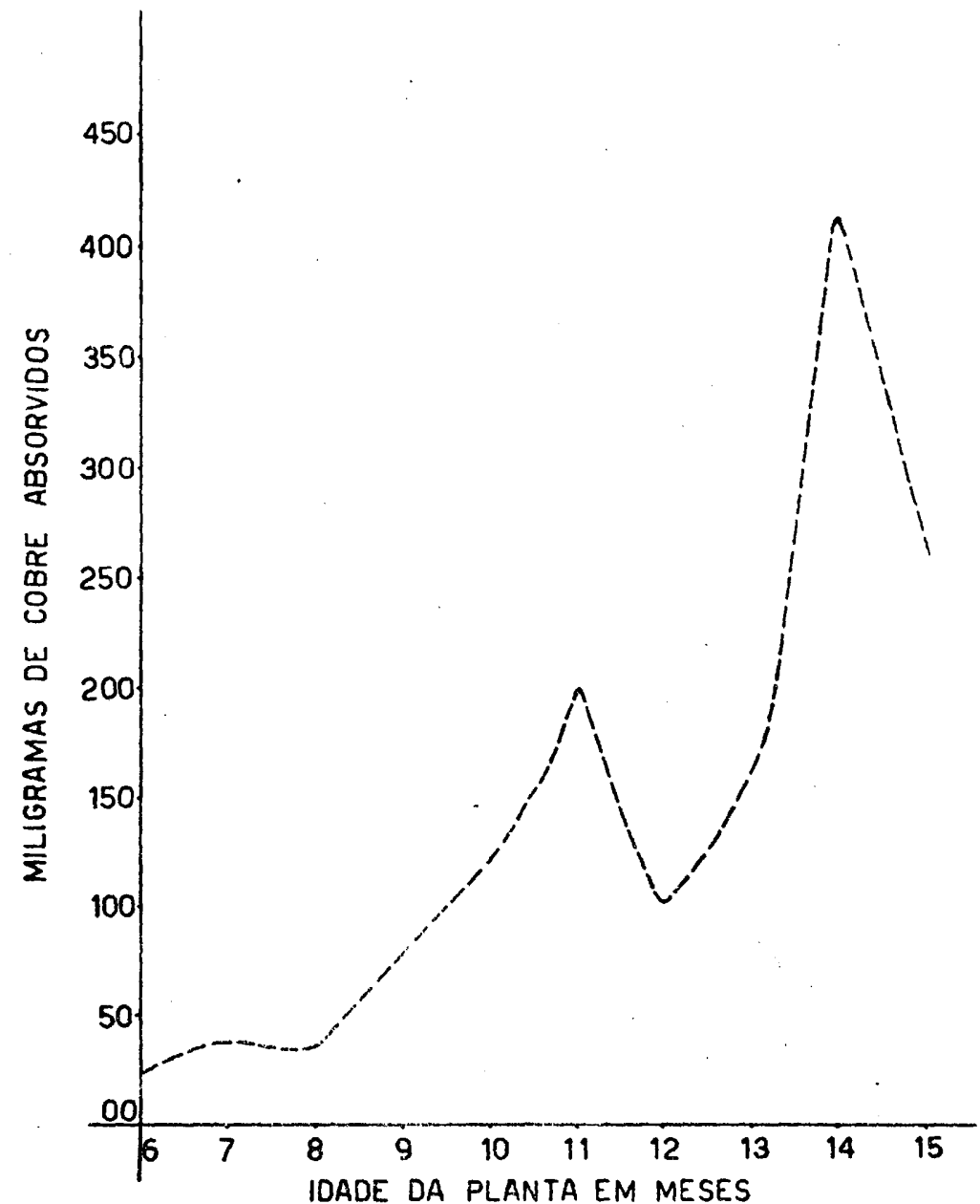

Frqura 3-Miligramas de cobre absorvidos pela parle aérea de 4 tcuceiras de cana-de-açúcar, variedade Co 419 , em funcăo da idade da planta. 
As quantidades em miligramas de cobre absorvidas pelas fôlhas, colmos e total da parte aérea de 4 touceiras, podem ser calculadas pelos valores fornecidos pelo quadro 1, relacionados com os pêsos de material sêco, conforme CATANI \& OUTROS (1959).

\section{QUADRO 2}

Miligramas de cobre absorvido pela parte aérea de 4 touceiras de cana de açúcar, variedade co 419, em função da idade.

\begin{tabular}{lcccc}
\hline $\begin{array}{c}\text { Época da colheita } \\
\text { das } \\
\text { amostras }\end{array}$ & $\begin{array}{c}\text { Idade da } \\
\text { planta } \\
\text { em meses }\end{array}$ & $\begin{array}{c}\text { Miligramas } \\
\text { colmo }\end{array}$ & $\begin{array}{c}\text { de cobre } \\
\text { fôlha }\end{array}$ & $\begin{array}{c}\text { absorvido } \\
\text { total }\end{array}$ \\
outubro & 6 & - & & \\
novembro & 7 & 15,0 & 9,4 & 24,4 \\
dezembro & 8 & 26,7 & 10,8 & 37,6 \\
fevereiro & 10 & 27,5 & 9,1 & 36,6 \\
março & 11 & 91,2 & 29,0 & 120,2 \\
abril & 12 & 178,9 & 17,7 & 196,6 \\
maio & 13 & 70,6 & 30,1 & 100,7 \\
junho & 14 & 136,1 & 24,8 & 160,9 \\
julho & 15 & 341,5 & 70,7 & 412,2 \\
& & 209,8 & 48,4 & 258,2 \\
\hline
\end{tabular}

Os resultados colocados no quadro 1, possibilitaram a obtenção de curvas que expressam a concentração de cobre no côlmo e na fôlha em função da idade da planta em meses (tig. 1 e 2).

Os resultados do quadro 2 , por sua vez permitiram estabelecer a curva de absorçäo do cobre em muigramas, para o total da parte aérea de 4 touceiras em Iunção da iảade (1ig. 3).

\section{4 - RESUMO}

O presente trabalho teve por objetivo a determinaçăo da concentração de cobre e o estudo das quantidades absorvidas do elemento citado, pela cana de açúcar Co 419, crescendo em condições de campo na região de Piracicaba, Estado de São Paulo. As amostras eram provenientes de 3 repetições, de um tratamento no qual as plantas sofreram adubação com nitrogênio, fósforo e potássio, variando as plantas de 6 a 15 meses de idade. 
O método utilizado na determinação do cobre, foi o do dietilditiocarbamato de sódio.

A concentração de cobre apresentou um relativo decréscimo, com o aumento de idade da planta, variando os teores de cobre no colmo de 7,4 a $62,8 \mathrm{ppm}$ e na fôlha de 10,0 a 30,0 ppm.

Quanto a absorção do cobre, a planta apresentou um aumento proporcional a idade. A mesma absorveu maior quantidade no $14 .^{\circ}$ mês, 412,2 miligramas de cobre, por 4 touceiras.

\section{5 - CONCLUSÕES}

Dos dados obtidos no presente trabalho, podem ser tiradas as seguintes conclusões:

a) A concentração de cobre nos colmos apresentou uma variação relativamente grande, com uma tendência de diminuição em função da idade. O teor máximo aparece no 6..$^{\circ}$ mês e o mínimo no $12 .^{\circ}$ mês de idade. Para as fôlhas a variação foi menor e o teor máximo de cobre apareceu no 6..$^{\circ}$ e $14 .^{\circ}$ mês e o mínimo no $13 .^{\circ}$ mês de idade.

b) Pode ser observado um pequeno paralelismo nas concentrações de cobre no côlmo e na fôlha, sendo que para o $12 .^{\circ}$ e $15 .^{\circ}$ meses de idade os teores de cobre foram maiores nas fôlhas.

c) As quantidades de cobre absorvidas pelo côlmo foram sempre maiores que pelas fôlhas e a planta absorveu maior quantidade de cobre no $14 .^{\circ}$ mês de idade. Esta absorção foi crescente com a idade da planta.

d) A quantidade máxima de cobre absorvida pela parte aérea de 4 touceiras foi de $412,2 \mathrm{mg}$.

\section{6 - SUMMARY}

This paper reports the determination of copper concentration and the study of its quantities taken up by the sugar cane Co 419, grown under field conditions in the region of Piracicaba, State of São Paulo, Brasil. 
The samples came from a fertilization (NPK) experiment plot with three repetitions, and were cut monthly, from the $6^{\text {th }}$ to the $15^{\text {th }}$ month of age.

The copper content was determined by the sodium diethyldithiocarbamate method.

It can be seen, from the data obtained, that the copper level showed a relative decrease with the aging of the plant. The coper content varied from 7.4 to $62.8 \mathrm{ppm}$ in the stalk and from 10 to $30 \mathrm{ppm}$ in the leaves.

The asorption of copper showed an increase proportional to the plant age. The highest uptake of copper occurred in the $14^{\text {th }}$ month of age, when it was absorbed 412 miligrams of copper by 4 stools.

\section{7 - LITERATURA CITADA}

BITTENCOURT, V.C., R.A. CATANI, D. PELLEGRINO \& N.A. DA GLóRIA, 1963 - A absorçāo de ferro pela cana de açúcar, Co 419, em função da idade. Nos prelos dos Anais da E.S.A. "Luiz de Queiroz", vol. 20 - 1963.

BONNER, J., 1950 - Plant Biochemistry. Academic Press INC., Publishers New York 10, N.Y., 1950. 490 pp.

BONNER, J. \& A.W. GALSTON, 1952 - Principles of Plant Physiology. Califórnia a Institute of Technology. W.H. Freeman and Co. San Francisco, 499 pp.

CATANI, R.A., H.C. ARRUDA, D. PELLEGRINO \& H. BERGAMIN FILHO, 1959 - A absorção de nitrogênio, fósforo, potássio, cálcio, magnésio, enxôfre e silício pela cana de açúcar, Co 419, e o seu crescimento em funçāo da idade. Anais da E.S.A. "Luiz de Queiroz", 16: 167-190.

EVANS, H., 1955 - Studies in the mineral nutrition of sugar cane in British Guiana - II. The mineral status of sugar cane as revealed by foliar analyses. Tropical Agriculture, 32: 295-322. (Separata).

EVANS, H., 1959 - Elements other than nitrogen, potassium and phosphorus in the mineral nutrition of sugar cane. Proceedings of the 10th Congress of the International Society of Sugar cane Technologists, 473-508.

GLóRIA, N.A., R.A. CATAN., H. BERGAMIN FILHO \& D. PELLEGRINO, 1963 - A absorção de molibdênio pela cana de āçúcar, variedade Co 419, em função da idade. No prelo dos Anais da E.S.A. "Luiz de Queiroz", vol. 20: 1963.

HUMBERT, R.P., 1963 - The Growing of Sugar Cane. Elsevier Plu. blishing Company. Amsterdam-London - New York. pp 223-225.

JOHNSON, C.M. \& ULRICH, 1959 - Analytical methods for use in plant analysis. California Agricultural Experiment Station. Bulletin 766: 64-66. 
PELLEGRINO, D., R.A. CATANI, H. BERGAMIN FILHO \& N.A. DA GLORIA, 1962 - A absorção do zinco pela cana de açúcar, Co 419, em função da idade. No prelo dos Anais da E.S.A. "Luiz PELLEGRINO, D., R.A. CATANI, H. BERGAMIN FILHO \& N.A. DA GLORIA, 1962 - A absorção do manganês pela cana de açúcar Co 419, em função da idade. No prelo dos Anais da E.S.A. "Luiz de Queiroz", vol. 19: 1962. 